\title{
Prolonged Analgesic Effect of PRF-108 and PRF-110 on Post-operative Pain in Pigs
}

David Castel · Michael Naveh · Arnon Aharon · Ofer Doron •

Sigal Meilin

To view enhanced content go to www.paintherapy-open.com

Received: October 30, 2015 / Published online: January 2, 2016

(c) The Author(s) 2015. This article is published with open access at Springerlink.com

\section{ABSTRACT}

Introduction: Local anesthetic infusion techniques have been reported to reduce opiate requirements and pain scores following different kinds of surgery, including orthopedic surgery, inguinal hernia, and Cesarean surgery in women.

Methods: PRF-108 and PRF-110 formulations were applied to the wound space in an

Electronic supplementary material The online version of this article (doi:10.1007/s40122-015-0043-9) contains supplementary material, which is available to authorized users.

D. Castel

The Neufeld Cardiac Research Institute and Department of Physiology and Pharmacology, Sackler School of Medicine, Tel-Aviv University, Tel-Aviv, Israel

M. Naveh · A. Aharon

PainReform, c/o Medica VP, Herzeliya, Israel

O. Doron

Lahav Research Institute, Kibutz Lahav, Negev, Israel

\section{S. Meilin ( $\square)$}

Neurology Division, MD Biosciences, Ness Ziona, Israel

e-mail: sigal@mdbiosciences.com incisional model in pigs to test the hypothesis that these formulations have better and longer analgesic effects than the commercially available ropivacaine solution $\left(\operatorname{Naropin}^{\circledR}\right.$, AstraZeneca).

Results: The data show significantly better analgesic activity with PRF-108 and PRF-110 compared to ropivacaine. The duration of the analgesic efficacy of PRF-108 and PRF-110 was at least five times longer than that was measured following treatment with ropivacaine. The data further suggest that active clearance from the injection site (the wound) is much slower for PRF-108 and PRF-110 than for the commercial ropivacaine solution.

Conclusion: Assessing the local concentration of PRF compounds and commercially available ropivacaine solution suggests that active clearance from the injection site (the wound) is much slower for PRF-108 and PRF-110 than for ropivacaine.

Funding: PainReform.

Keywords: Incision; Pain; Pig; PRF-108; PRF-110; Ropivacain; Surgery 


\section{INTRODUCTION}

Local anesthetic infusion techniques have been reported to reduce opiate requirements and pain scores following different kinds of surgery, including orthopedic surgery [1, 2], inguinal hernia [3], and Cesarean surgery in women [4]. Decades ago, wound infiltration with either ropivacaine or bupivacaine was reported as a good pain control approach following surgery [5]. In the present study, we assessed the hypothesis that PRF-108 and PRF-110 formulations afford prolonged pain relief following surgery.

PRF-108 and PRF-110 are new extended-release oily formulations of ropivacaine and are generally recognized as safe excipients intended for local administration into surgical wounds. The formulations are designed to slowly release the ropivacaine. It is expected that the provision of local analgesia over a long time span will reduce the need for systemic analgesics, especially opiates, and that this may also shorten the hospitalization time. The two formulations are very similar and differ in only a single ingredient,

DMPG (1,2-dimyristoyl-sn-glycero-3 phosphoglycerol $\mathrm{NH}_{4} / \mathrm{Na}$ salt). To test this hypothesis, the above formulations were applied to the wound space in an incisional model in pigs [6].

\section{METHODS}

\section{Drugs}

PRF-108 at a concentration of $4 \%$ ropivacaine in either $4 \%$ ethanol (Group 3) or 6\% ethanol (Group 4) or PRF-110 in 6\% ethanol was injected sub-cutaneously in the incision area at a volume of $2.5 \mathrm{~mL}$ on each side. The ropivacaine hydrochloride solution Naropin $^{\circledR}$ $1 \%$, AstraZeneca) was diluted in saline to achieve a concentration of $0.5 \%$. Vehicle-treated animals were treated with $6 \%$ ethanol/viscous material.

\section{Drug Formulation}

All drug combinations were prepared by Nextar ChemPharma Ltd., Israel, from the following components: ropivacaine hydrochloride $\mathrm{H}_{2} \mathrm{O}$ (Haorui Pharma-Chem. Inc.), lecithin phospholipon 90G (PL90G; Phospholipid $\mathrm{GmbH}$ ), castor oil (Spectrum Chemical Mfg. Corp.), cysteine hydrochloride (Spectrum Chemical Mfg. Corp.), absolute ethanol (Merck), and, for PRF-108 only, DMPG (1,2-dimyristoyl-sn-glycero-3 phosphoglycerol $\mathrm{NH}_{4} / \mathrm{Na}$ salt; Avanti). All components met the 'generally recognized as safe' criteria of the Food and Drug Administration.

The composition of $4 \%$ ropivacaine PRF-108 was ropivacaine hydrochloride monohydrate $4.78 \%(\mathrm{w} / \mathrm{w})$, PL90G $50.89 \%$ or $48.89 \%(\mathrm{w} / \mathrm{w} ; 4 \%$ or $6 \%$ ethanol formulation, respectively), castor oil $35.21 \%(\mathrm{w} / \mathrm{w})$, cysteine hydrochloride $0.10 \%(\mathrm{w} / \mathrm{w})$, and ethanol $4 \%$ or $6 \%(\mathrm{w} / \mathrm{w})$. The composition of $4 \%$ ropivacaine PRF-110 was ropivacaine $\mathrm{HCl}$ monohydrate $4.78 \%$ (w/w), PL90G $53.91 \%$ $(\mathrm{w} / \mathrm{w})$, castor oil $35.21 \%(\mathrm{w} / \mathrm{w})$, cysteine $\mathrm{HCl}$ $0.10 \% \quad(\mathrm{w} / \mathrm{w})$ and ethanol $6.0 \% \quad(\mathrm{w} / \mathrm{w})$. Ingredients were weighed and dissolved in excess ethanol, blended by sonication in a pharmaceutical reactor at $50^{\circ} \mathrm{C}$. Sonication was continued for $4 \mathrm{~h}$, and additional 1-h periods if needed, until a clear solution was obtained. The solution was dried in a rotary evaporator (rotor $60 \mathrm{rpm}$, vacuum 40-200 mbar) and the final alcohol content was corrected to $4 \%$ or $6 \%$ as indicated. 


\section{Animals and Housing}

Danish Landrace $X$ large white crossbred weaned male pigs $(n=46)$ from the domestic herd at Lahav Labs (Negev, Israel) were used. Prior to the beginning of the experiment, all animals were kept under conventional pig production conditions. All pigs were $7-8$ weeks old and weighed $10 \pm 1 \mathrm{~kg}$ at the start of the study. The animals were housed in open pens $(1.4 \times 2.4 \mathrm{~m}) 7$ days prior to study initiation. The pigs were kept in groups of two or three during the acclimatization period and throughout the experiment. Feeding occurred three times daily using special pig food (Dry Sows; Ct \# 5420; Milobar, 7880, Oshrat, Israel), and the pigs were provided opportunities to root and chew for enrichment. Fresh water was provided ad libitum by an automated system. The pigs were kept on a 12-h light/dark cycle. The study was approved by the Institutional Animal Care and Use Committee (IACUC) and adhered to guidelines of the Committee for Research and Ethical Issues of the International Association for the Study of Pain (IASP) [7]. All tests were performed blind, that is, the technician was unaware of the individual animal's treatment.

\section{Habituation Protocol}

The pigs were habituated to the protocol for 5 days prior to surgery. The researchers, the veterinarian, and the animal care technicians played with the pigs in their home pen for at least 15 min, twice a day, on each day of the acclimatization period and throughout the experiment. As a result, the pigs became familiar with their observers. This ensured calm and consistent handling of the animals. The same technicians cared for the animals throughout the entire study period. No other people were allowed into the housing facility. To familiarize the pigs with the protocol and technicians, they were trained to walk to the preparation room daily during the habituation period. The pigs were always returned to their original pens with their original pen mates. The habituation process was intended to reduce the stress level of the pigs.

\section{Anesthesia, Surgery, and Drug Application}

On the day of surgery, the pigs walked freely to the preparation room. The technicians carried each animal in their hands and placed an anesthetic facemask (Stephan Akzent Color) on the pig's mouth and nose. Each animal was anesthetized with a $3 \%$ isoflurane/100\% oxygen mixture. The technician held the pig until it was relaxed and sleepy. Then, the technician placed the pig in a sternal position, still connected to the anesthesia mask. The pig was shaved and swabbed with $70 \%$ ethanol and then carried to the operating room. The pig was placed on the operating table and a sterile environment was maintained. The area of the incision was swabbed with antiseptic liquid polidine solution (Polysept solution, Rekah Pharmaceutical Industry Ltd.) and the non-operated areas were covered with sterile sheets. Blood oxygen saturation was monitored throughout the anesthesia (Spacelab Medical).

The operation is fully detailed in Castel et al. [6]. Briefly, a 6- to 7-cm incision was made through only the skin and fascia, keeping the muscle intact. The incision was made on the left side of the lower back toward the caudal end. Immediately after the incision was made, the drug was applied to the pocket resulting from the skin incision. Following drug administration, the incisions were closed using 3-0 silk sutures (Assut UK Ltd.) and a continuous suturing technique. Following the 
incision, all pigs received the antibiotic marbofloxacin $\quad\left(10 \% \quad \mathrm{w} / \mathrm{v} ; \quad\right.$ Marbocyl $^{\circledR}$, Vétoquinol UK Ltd.) at a total dose of $0.5 \mathrm{~mL}$ per pig, which was administered into the neck muscle via intramuscular injection. Each animal was kept under anesthesia for the duration of the surgery. The entire procedure, from the time that the animal was introduced to the facemask until the facemask was removed, was performed in approximately $20 \mathrm{~min}$. The animals were then returned to their home pen for recovery.

\section{Assessment of Mechanical Sensitivity}

Mechanical sensitivity was assessed using von Frey filaments [Touch Test (von Frey) Sensory Evaluator Kit, model 58011, Stoelting Co.]. The tests were performed in the pig's home pen. Von Frey filaments ranging from a minimum of $1 \mathrm{~g}$ $($ diameter $=0.229 \mathrm{~mm}$; force $=9.804 \mathrm{mN})$ to a maximum of $60 \mathrm{~g} \quad$ (diameter $=0.711 \mathrm{~mm}$; force $=588.253 \mathrm{mN}$ ) were used. The intact side (contralateral to the side of incision) was introduced first to the von Frey filaments as a control. The filaments were then applied approximately $0.5 \mathrm{~cm}$ proximal to the incision on the skin [6]. Each filament was applied three times with a 5- to 10-s interval between applications. If withdrawal was not achieved, a thicker filament was applied. If withdrawal was achieved, a thinner filament was applied. By alternating the filaments, the force required to achieve a withdrawal reaction was determined. This procedure was carried out at different time-points during $48 \mathrm{~h}$ of post-surgery follow-up.

\section{Incision Healing}

The incisions of all animals were scored throughout the study period $(48 \mathrm{~h})$. Three additional sham-operated animals and three animals treated with PRF using the 6\% ethanol formulation were culled 14 days post-administration and the area of the incision was taken for further histology analysis. The incision of these animals was closely observed and scored during these 14 days of follow-up. The score was composed of two categories: redness $(0=$ normal; $1=$ slight redness at the area of the incision; $2=$ diffuse redness $)$ and swelling $(0=$ no swelling; 1 =slight swelling; $2=$ pronounced swelling). The final score of each animal was the sum of the scores on each category. The incision area was photographed daily.

At the end of the study, photographs were taken again, the animals were euthanized, and the incision and surrounding areas were taken for histological analysis of wound healing. The skin samples were collected from each wound area such that the surgical incision was located in their center. The samples all had similar dimensions (ca. $5 \mathrm{~cm}$ long $\times 3 \mathrm{~cm}$ wide $\times 2 \mathrm{~cm}$ deep) and were individually identified. Their cranial edge was marked with a tissue dye (Davidson Marking System). The samples were then pinned to a flat piece of polystyrene foam to maintain their flat shape and were placed individually into containers with $10 \%$ neutral buffered formalin for fixation. The cranial edge was also marked on the polystyrene foam. Each sample was evaluated in three $5-\mu \mathrm{m}$ paraffin-embedded sections. Sample A was approximately $1 \mathrm{~cm}$ from the marked (proximal) edge, sample $\mathrm{B}$ was from the middle, and sample $C$ was approximately $1 \mathrm{~cm}$ from the contralateral distal edge. The healing of each section of the samples was graded. These healing scores served to determine a grade for the entire sample. The grading was as follows: excellent $(4)=$ full healing via a narrow fibrous scar without significant inflammation; very good (3) = full healing, similar to the above 


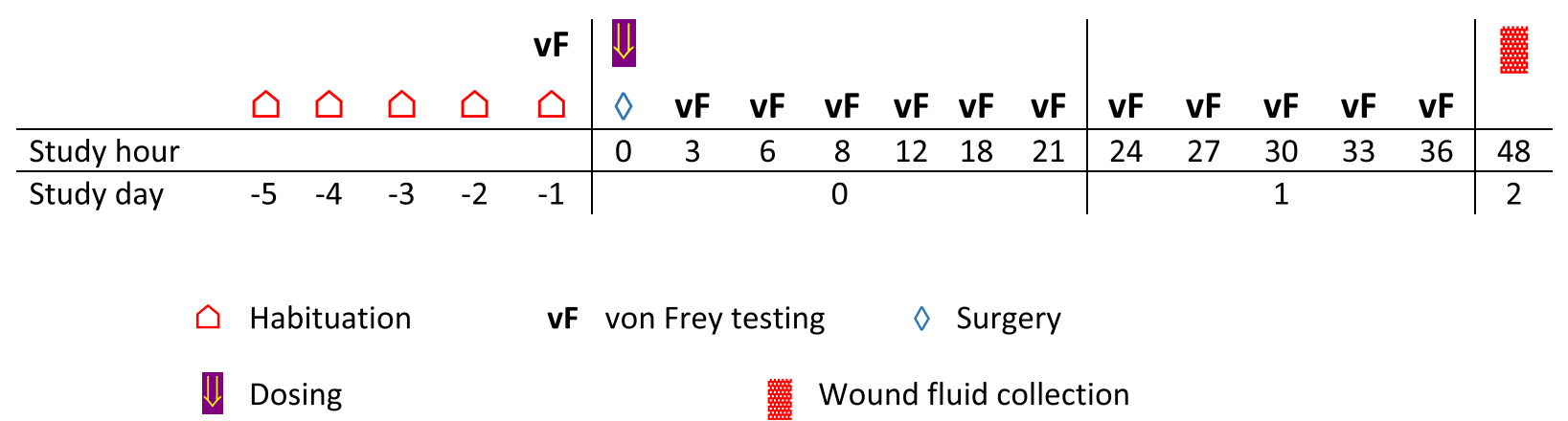

Fig. 1 Study design. The figure shows the study activity over a period of $48 \mathrm{~h}$. However, six additional animals were observed for a period of 14 days at day 14 . These animals

but with some less desirable variations, e.g., wider scar but still discrete and/or mild inflammation; good (2) = full healing with extensive local fibrosis, in some cases with some mononuclear inflammation; and poor $(1)=$ all other types of tissue reactions.

\section{Blood and Wound Liquid Collection}

Venous blood samples (3.5 mL samples) for measurement of the plasma concentration of ropivacaine were drawn at 13 time-points over a period of 38-h post-test item administration. Blood samples were drawn into cooled test tubes (at approximately $4{ }^{\circ} \mathrm{C}$ ) pre-loaded with EDTA-K3. Samples were centrifuged within 15 min of sampling in a cooled centrifuge (at approximately $4{ }^{\circ} \mathrm{C}$ ). The supernatant (plasma) was collected for further analysis.

At $48 \mathrm{~h}$, the animals were culled and the wounds were opened. The wound liquid was collected using a 10G needle and a pre-EDTA-K3 loaded syringe. The liquid was then centrifuged and kept at $-80{ }^{\circ} \mathrm{C}$ until further analysis.

\section{Analysis of Ropivacaine in PRF-108 and PRF-110 Plasma Samples}

Quantitative analysis of ropivacaine levels in plasma was performed using a HPLC/MS/MS were culled and the incision area was removed for wound healing analysis

method on a Phenomenex Synergi column $150 \times 2 \mathrm{~mm}, \quad 4 \mu \mathrm{m}, \quad$ Polar-RP, 80A, P.N. 00F-4336-B0, flow rate $0.35 \mathrm{~mL} / \mathrm{min}$, at $40 \pm 4{ }^{\circ} \mathrm{C}$, run time $4 \mathrm{~min}$, mobile phase acetonitrile/2.5 $\mathrm{mM}$ ammonium acetate/formic acid, 40/60/0.2 v/v/v. Samples were diluted in pig plasma and run against a standard ropivacaine in pig plasma curve.

\section{Study Design}

Animals were assigned to five groups as follows: vehicle-treated animals (Group 1); Naropin-treated group (Group 2); PRF-108 in $4 \%$ ethanol (Group 3); PRF-108 in 6\% ethanol (Group 4); and PRF-110 in 6\% ethanol (Group 5). There were 4-6 animals per group. The study was performed in four parts: part 1, habituation (study day -5 until study day 0); part 2, surgery and drug application; part 3, pain assessment for $48 \mathrm{~h}$; and part 4 , blood collection and tissue wound liquid collection (Fig. 1).

Two additional sham-operated animals and four additional animals were dosed with PRF-108 using the 6\% ethanol formulation. These animals were followed for 14 days post-injection. At day 14, the animals were culled and the incision area was taken for further histology analysis of wound healing. 


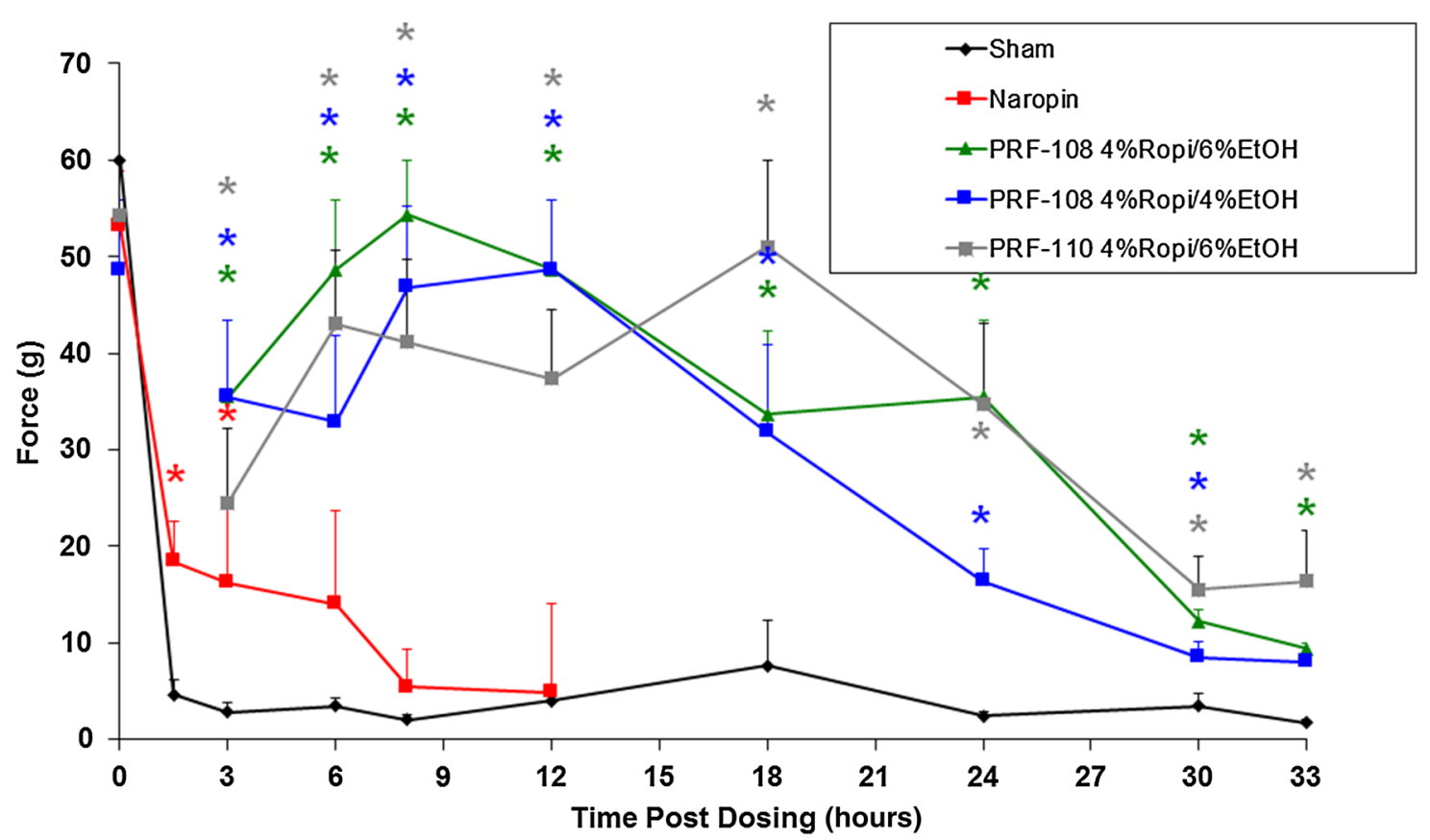

Fig. 2 The effect of PRF-108, PRF-110, and Naropin on withdrawal force following von Frey testing. ${ }^{*} P<0.05$ vs. sham-operated animals. EtOH ethanol, Ropi ropivacaine

\section{Data Analysis}

The results are presented as mean \pm standard error of the mean. Comparisons between groups were performed using one-way analysis of variance followed by Dunnett's test (GraphPad Prism $^{\circledR}$, GraphPad Software, Inc.) and assuming a normal distribution of data. Pharmacokinetic data were analyzed using the Wilcoxon non-parametric test. A $P$ value $<0.05$ was considered significant.

\section{RESULTS}

Assessment of pain for a period of $48 \mathrm{~h}$ post-surgery and placebo application showed a significant decrease in withdrawal force. At baseline, the withdrawal force of the animals was $60.00 \pm 0.00 \mathrm{~g}$. One hour post-dosing, the mean group withdrawal force was as low as $2.80 \pm 1.00 \mathrm{~g}$ at $3 \mathrm{~h}$ post-surgery for the placebo-treated animals ( $P<0.05$ vs. baseline).
This low withdrawal force was also detected on study day $33(1.67 \pm 0.30 \mathrm{~g})$. Treatment with PRF-108 using a formulation of $4 \%$ ropivacaine/ $6 \%$ ethanol or $4 \%$ ropivacaine/4\% ethanol was effective in increasing the withdrawal force at $3 \mathrm{~h}(35.50 \pm 7.7$ and $35.50 \pm 7.9 \mathrm{~g}$, respectively, $P<0.05$ vs. the saline group). Treatment with PRF-110 was as effective as PRF-108 with a formulation of $4 \%$ ropivacaine/ $6 \%$ ethanol (Fig. 2). At $24 \mathrm{~h}$ post-surgery, animals treated with $4 \%$ ropivacaine/4\% ethanol experienced reduction in withdrawal force compared to animals treated with $4 \%$ ropivacaine/ $6 \%$ ethanol. However, this change was not significant $\quad(16.33 \pm 3.8$ vs. $35.50 \pm 7.9 \mathrm{~g}$, respectively). The mean group withdrawal force for the animals treated with PRF-110 was $34.67 \pm 8.4 \mathrm{~g}$ at $24 \mathrm{~h}$ post-surgery.

Naropin treatment was not as effective as PRF-108 or PRF-110 in increasing the withdrawal force. At $3 \mathrm{~h}$ post-application, treatment with Naropin resulted in a mean 


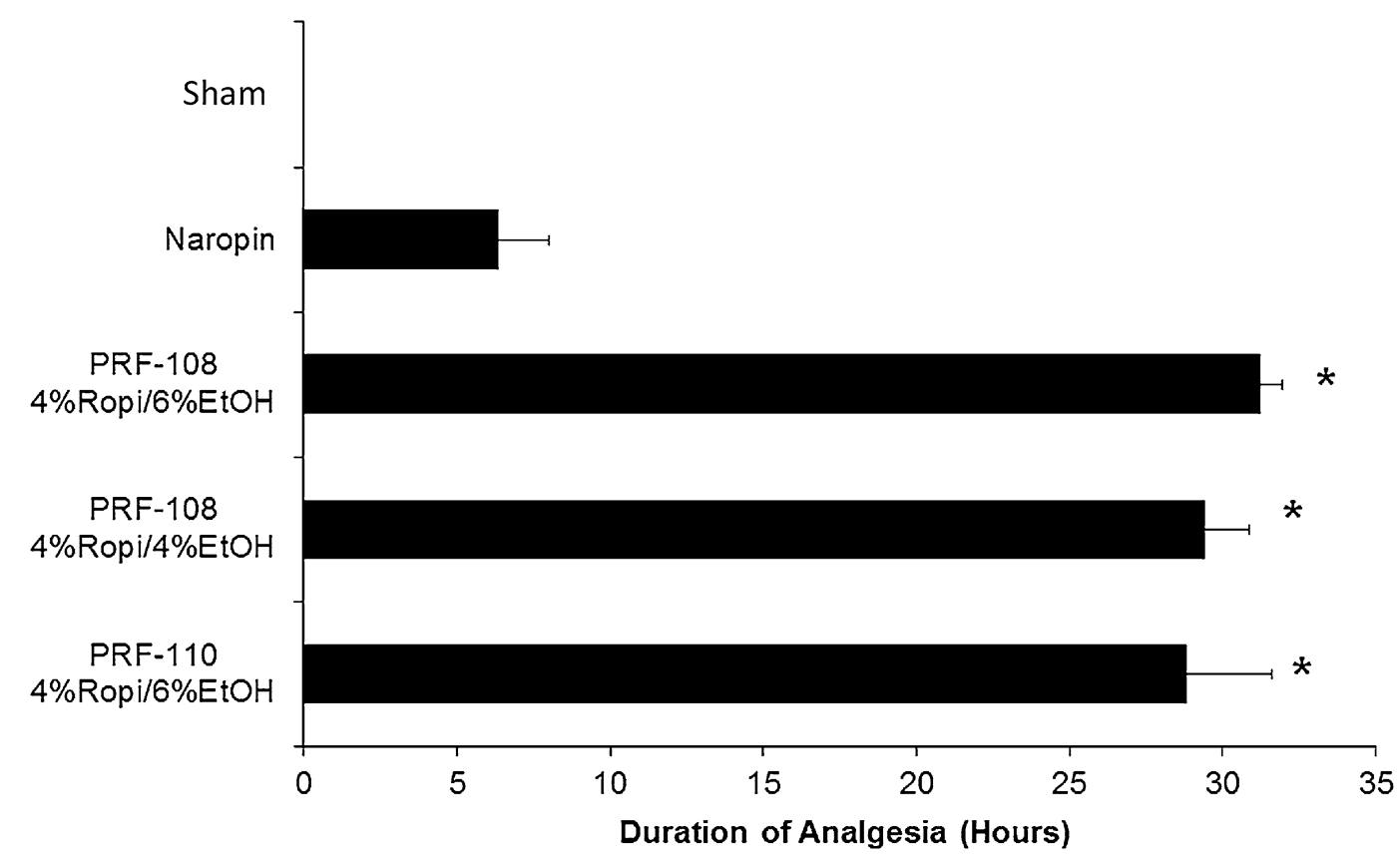

Fig. 3 The effect of PRF-108, PRF-110 and Naropin on the duration of analgesia. PRF-108 and PRF-110 showed a significantly lower analgesia period, exceeding $24 \mathrm{~h}$, vs.

group withdrawal force of $23.50 \pm 7.6 \mathrm{~g}$. At $8 \mathrm{~h}$ post-Naropin application, there was no significant difference between the withdrawal force of the saline-treated group and the Naropin-treated group. In comparison, the duration of analgesia following treatment with PRF-108 or PRF-110 was 30-33 h (Fig. 3).

A pharmacokinetic study exploring the level of ropivacaine in the plasma following treatment with either PRF-108 or Naropin suggested no difference in the maximum plasma concentration $\left(C_{\max }\right)$ between PRF-108 and Naropin (2919 vs. 3162 ng/mL, respectively; Fig. 4). A $P$ value of 0.0520 was found when comparing the time at which $C_{\max }$ was observed $\left(T_{\max }\right)$ for PRF-108 and Naropin (6.50 vs. $0.5 \mathrm{~h}$, respectively; Table 1$)$. Forty-eight hours post-dosing, analysis of the blood ropivacaine concentration showed a very low level of ropivacaine following treatment with PRF-108, PRF-110, or Naropin. No
Naropin. ${ }^{*} P<0.05$ vs. sham-operated animals. EtOH ethanol, Ropi ropivacaine

difference was found between the levels of ropivacaine in the animals treated with PRF-108 using 6\% ethanol versus the $4 \%$ ethanol formulation (102 \pm 34 vs. $70 \pm 20 \mathrm{ng} /$ $\mathrm{mL}$ ). No difference was found between PRF-110 and PRF-108 using the 6\% ethanol formulation ( $31 \pm 5$ vs. $102 \pm 34 \mathrm{ng} / \mathrm{mL}$ ). The area under the curve of the plasma concentration of ropivacaine demonstrated a significant increase following PRF-108 $(44,579 \pm 3662)$ versus Naropin $\quad(5918 \pm 1008 ; \quad P<0.05)$ administration (Table 1). Analysis of the wound fluid revealed no significant difference in the ropivacaine concentration between the following treatment groups: PRF-108 4\% ropivacaine $/ 4 \%$ ethanol, PRF-108 4\% ropivacaine $/ 6 \%$ ethanol, and PRF-110. A comparison of the wound concentration of ropivacaine in the PRF-treated and the Naropin-treated groups showed a significantly higher concentration in animals treated with 


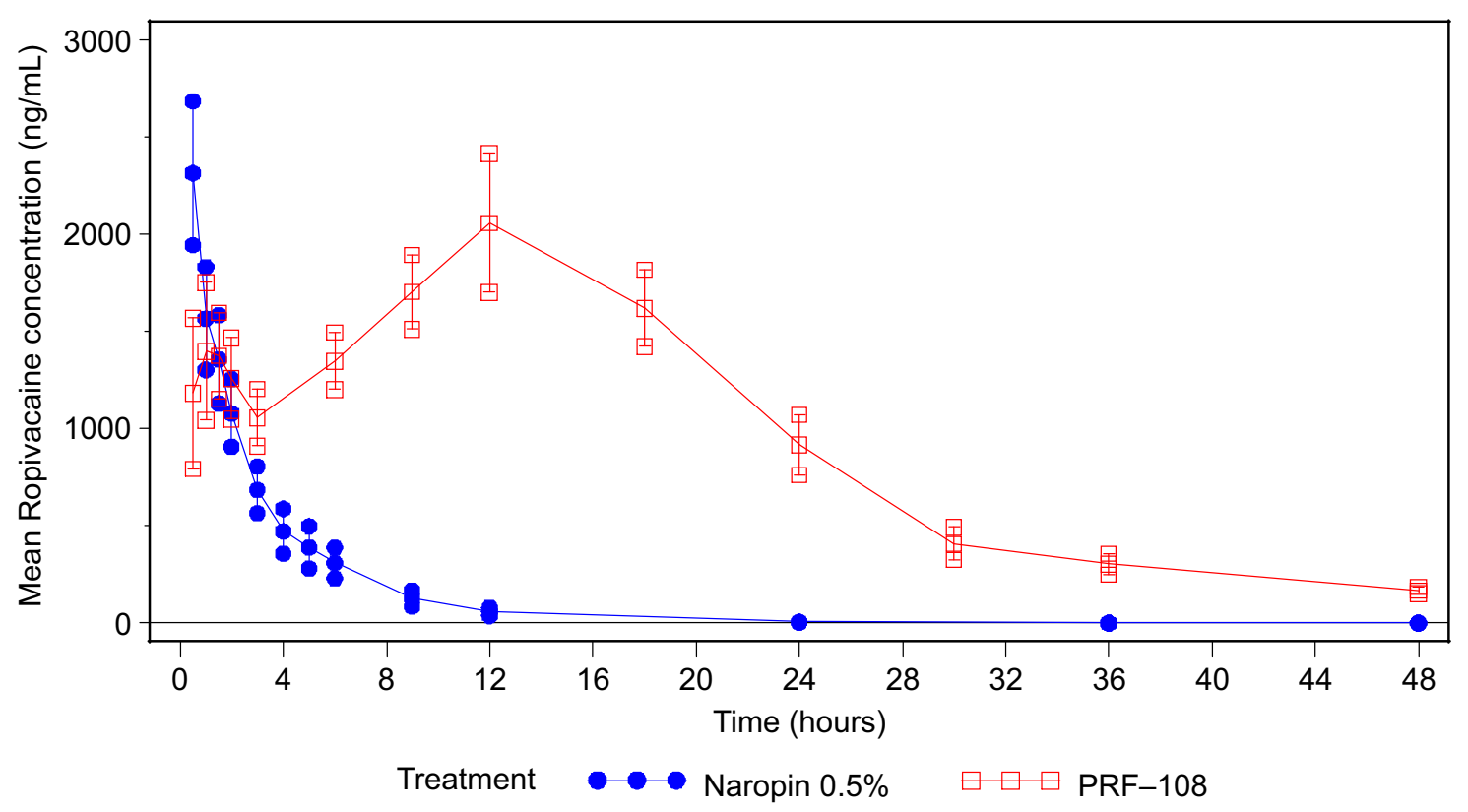

Fig. 4 Changes in ropivacaine plasma levels over time following PRF-108 or Naropin dosing

$4 \%$ ropivacaine $/ 6 \%$ ethanol and PRF-110

$(7777 \pm 2822 \quad$ and $3799 \pm 599 \mathrm{ng} / \mathrm{mL}$, respectively, $\quad$ vs. $\quad 15 \pm 13 \mathrm{ng} / \mathrm{mL}, \quad P<0.05$; Fig. 5b). However, the ratio of the ropivacaine concentration in the wound fluid versus the ropivacaine blood concentration at $48 \mathrm{~h}$ post-dosing was higher after treatment with PRF-110 or PRF-108 than following treatment with Naropin (Fig. 5c).

No abnormalities were noticed during the 48-h observation of the incision in any of the treatment groups during the 14 days of wound observation. No swelling or redness was noted. At 14 days post-dosing, the wounds of four additional animals treated with PRF-108 in 6\% ethanol formulation and two sham-operated animals were harvested. Gross observation of the incisions suggests a clean and almost full incision bridge with no difference between the sham-operated animals and the PRF-108 in 6\% ethanol-dosed animals (Fig. 6). Table 2 details the histological findings. The total histology score of the PRF-108 in 6\% ethanol group ranged between 2 and 4 . In comparison, the total scores of the sham-operated animals ranged between 2 and 3. Overall, the histology analysis suggests that treatment with PRF-108 in $6 \%$ ethanol did not affect the healing process.

\section{DISCUSSION}

The current study was designed to investigate the activity of local treatment with PRF-108 or PRF-110 using the post-operative pain model in pigs. The activity of these formulations was compared to the commercially available ropivacaine solution, Naropin. An additional aim was to assess the significance of differences in the ethanol content in the final formulation on its efficacy and pharmacokinetics. All formulations in this study contained 4\% ropivacaine. The data show: (1) a significantly better analgesic effect of PRF-108 and PRF-110 vs. Naropin. (2) The duration of analgesia of PRF-108 and PRF-110 was significantly longer than that of Naropin. (3) A significantly longer Tmax of PRF-108 vs. Naropin. (4) At 48 h post-application, the wound concentration of 
Table 1 Pharmacokinetic data of Naropin and PRF-108

\begin{tabular}{|c|c|c|c|c|c|}
\hline & $C_{\max }(\mathrm{ng} / \mathrm{mL})$ & $T_{\max }(\mathrm{h})$ & AUC $\mathrm{Clast}$ & $\mathrm{AUC}_{\text {inf }}$ & $T_{1 / 2}(\mathrm{~h})$ \\
\hline \multicolumn{6}{|l|}{ Naropin $0.5 \%$} \\
\hline$N$ & 4 & 4 & 4 & 4 & 4 \\
\hline Mean & 2314.25 & 0.50 & 5917.69 & 5939.67 & 2.69 \\
\hline SD & 739.67 & 0.00 & 2016.35 & 2030.44 & 0.22 \\
\hline Median & 2283.00 & 0.50 & 5879.13 & 5898.40 & 2.68 \\
\hline Min & 1530.00 & 0.50 & 3574.75 & 3581.98 & 2.49 \\
\hline Max & 3161.00 & 0.50 & 8337.75 & 8379.89 & 2.92 \\
\hline Lower 95\% CI & 1137.28 & & 2709.23 & 2708.79 & 2.34 \\
\hline Upper 95\% CI & 3491.22 & & 9126.14 & 9170.55 & 3.05 \\
\hline \multicolumn{6}{|l|}{ PRF-108 } \\
\hline$N$ & 4 & 4 & 4 & 4 & 4 \\
\hline Mean & 2318.50 & 6.50 & $44,578.81$ & $47,182.33$ & 10.93 \\
\hline $\mathrm{SD}$ & 457.05 & 6.35 & 7323.90 & 7349.25 & 2.47 \\
\hline Median & 2262.00 & 6.50 & $45,325.88$ & $47,750.04$ & 10.93 \\
\hline Min & 1831.00 & 1.00 & $36,054.00$ & $38,571.23$ & 8.13 \\
\hline $\operatorname{Max}$ & 2919.00 & 12.00 & $51,609.50$ & $54,658.00$ & 13.74 \\
\hline Lower 95\% CI & 1591.23 & -3.61 & $32,924.85$ & $35,488.02$ & 7.00 \\
\hline Upper 95\% CI & 3045.77 & 16.61 & $56,232.77$ & $58,876.63$ & 14.87 \\
\hline$P$ value & NS & 0.0520 & 0.0671 & 0.0671 & 0.0671 \\
\hline
\end{tabular}

$A U C_{i n f}$ area under curve extrapolated to infinity from dosing time, based on the last observed concentration, $A U C_{\text {last }}$ area under curve last: from dosing to last measurable concentration, $C I$ confidence interval, $C_{\max }$ maximum plasma concentration, $N S$ not significant, $S D$ standard deviation, $T_{1 / 2}$ half-life, $T_{\max }$ time at which $C_{\max }$ was observed

ropivacaine was a hundred times higher following treatment with PRF-108 or PRF-110 vs. treatment with ropivacaine. (5) No difference was found between PRF-108 in 4\% ethanol formulation vs. PRF-108 using 6\% ethanol.

There is extensive evidence suggesting that pigs' skin resembles the human skin in structure, function $[8,9]$, innervation [10] and response to mechanical and thermal stimulation [6, 11-13]. Additionally, pigs have become a standard wound healing model due to the similarities to humans, including re-epithelialization rather than contraction [14]. Indeed, the level and duration of the effect of a single dose of Naropin are in line with what was found in humans. A double-blind randomized trial of wound infiltration with ropivacaine after breast cancer surgery with axillary node dissection suggests significant pain relief for $6 \mathrm{~h}$ post-treatment [15]. Pharmacokinetic studies in humans following spinal ropivacaine administration show a plasma peak at $0.5 \mathrm{~h}$ 

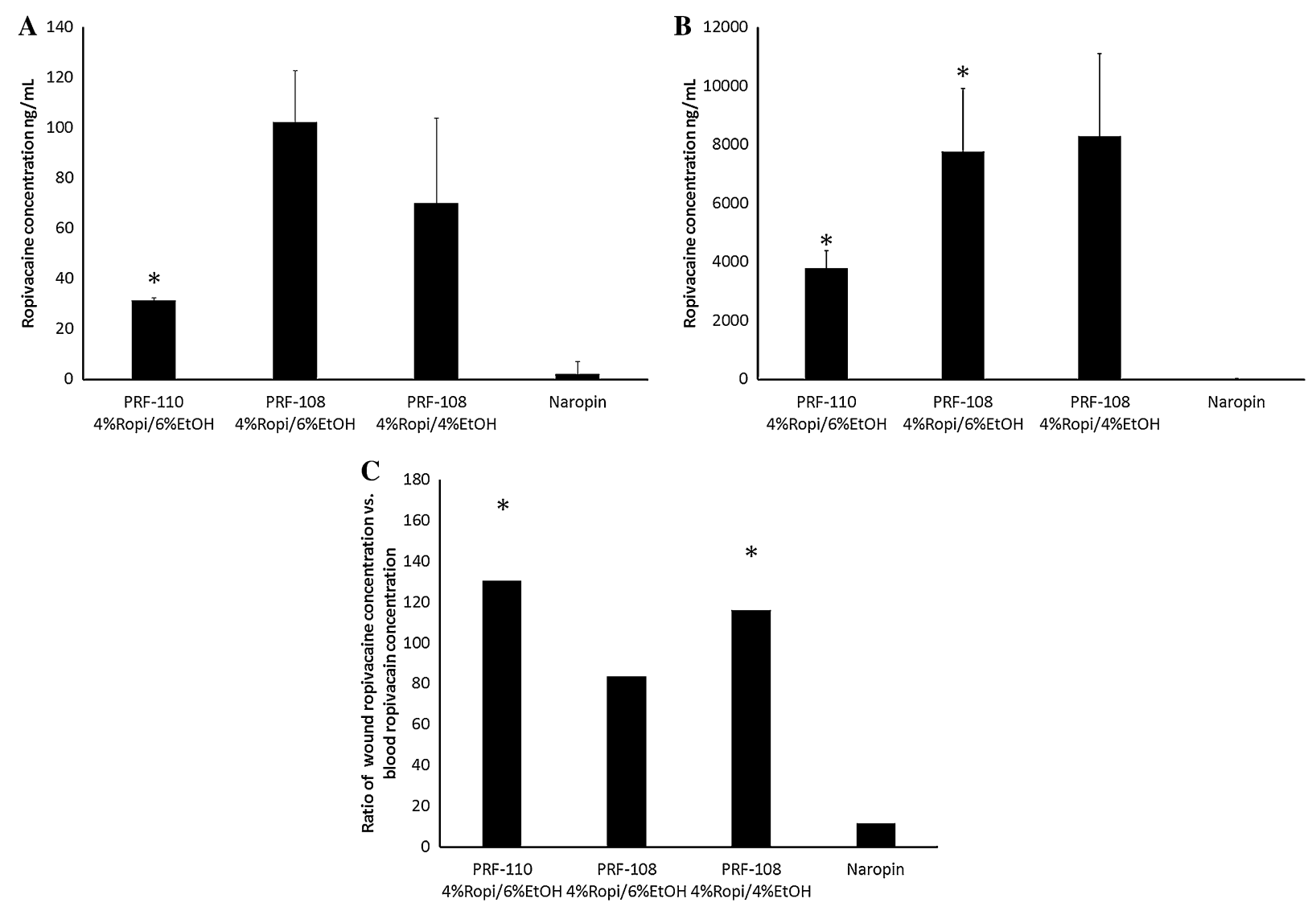

Fig. 5 Concentration of ropivacaine in the plasma (A) and the wound (B) 48 h post-treatment with PRF-108/4\% ethanol, PRF-108/6\% ethanol, PRF-110 or Naropin. ${ }^{*} P<0.05$ vs. the Naropin-treated group. EtOH ethanol, Ropi ropivacaine

post-administration and at $4 \mathrm{~h}$ post-administration the level of ropivacaine in the plasma was greatly reduced [16]. This is in line with the data described in this work. Continuous wound infusion of ropivacaine results in a longer presence of ropivacaine in the blood that is dependent on the duration of the infusion. The advantage of a local infusion is the relatively low systemic exposure [17]. A recent comparison between the post-operative analgesia using local anesthetics such as ropivacaine or bupivacaine following a continuous wound infusion approach with traditional patient-controlled analgesia (PCA) suggests that continuous wound infusion is as effective for post-operative analgesia as traditional PCA. Furthermore, this therapy reduced the incidences of drowsiness, dizziness, respiratory depression and decreased the intensive care unit stay and hospital expenditure [18, 19]. These studies emphasize the importance of prolonged ropivacaine activity immediately post-surgery. A study with a patient who underwent posterior lumber instrumented fusion for degenerative disc disease suggests that routine use of epidural infusion anesthesia for lumbar spine surgery has too many risks and offers very little advantages over PCA [20]. Gulle et al. [21] also showed that a combination of epidural ropivacaine and oral oxycodone can reduce the pruritus which is often reported following epidural analgesia with bupivacaine, epinephrine and fentanyl after lumbar fusion surgery. In knee arthroplasty 

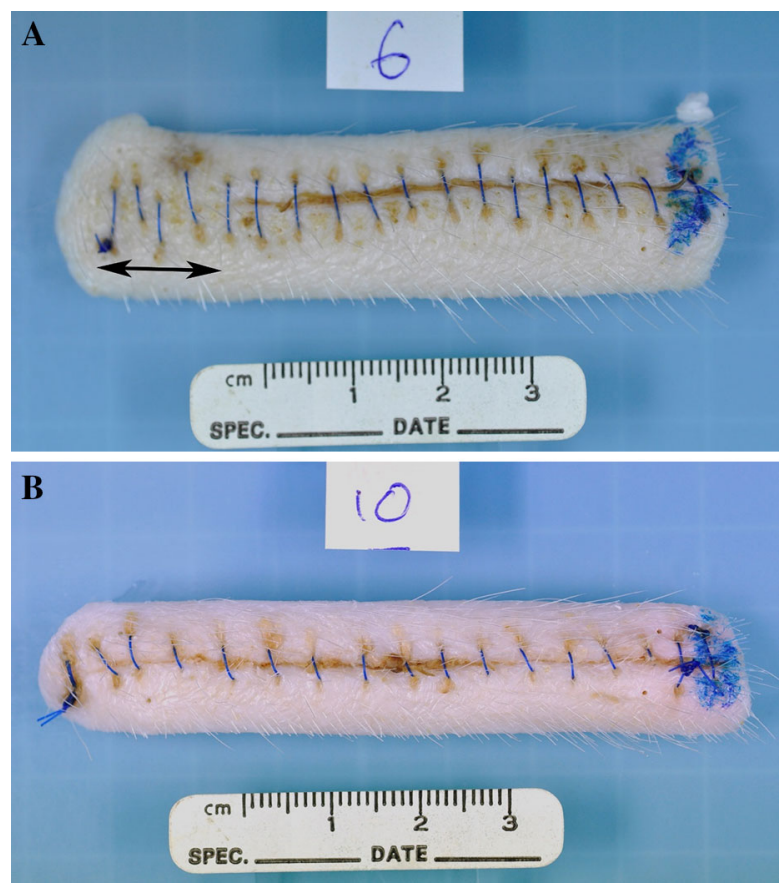

Fig. 6 Representative photographs of macroscopic observations. a A 7.5-cm-long sample from an animal treated with $4 \%$ ropivacaine $/ 6 \%$ ethanol (Group 3). The incision is well apposed and visible up to a point. Sutures continue for approximately $1.8 \mathrm{~cm}$ beyond the visible incision (marked). Small dried scabs in suture holes and to a lesser degree along the entire visible incision. No thickening is noted. b A sample from an animal of the sham group (Group 1) with an 8.4-cm-long incision. The incision is well apposed and visible throughout, except in the $1 \mathrm{~cm}$ away from the mark where it is barely perceptible (marked). A slightly larger scab in approximately one-third of the incision line and small dried scabs limited to suture holes. No thickening is noted

surgery, local injection of analgesics periarticularly at the end of the operation and intraarticularly at $21 \mathrm{~h}$ post-operatively provided excellent pain relief and earlier home discharge. In addition, the authors reported a high degree of patient satisfaction after 6 months [2]. The current study shows that a single dose of PRF-108 or PRF-110, a slow-release ropivacaine formulation, has a prolonged analgesic effect which can be detected for up to $30 \mathrm{~h}$, without the need for additional dosing. Local dosing of PRF-108 and
PRF-110 immediately before closure of the surgery wound has the advantages of prolonged ropivacaine activity and balancing the infusion catheterization risk.

In this study, four additional animals were operated and injected with PRF-108 using the $6 \%$ ethanol formulation. Ethanol is known to interfere with wound healing. Most studies refer to the effect of systemic exposure to ethanol as an inhibition factor in wound healing. It is suggested that early dermal inflammatory responses, including MPO activity, production of MIP-2, KC, and IL-1beta, are impaired in mice given ethanol before injury, which may also have detrimental effects on later stages of wound healing [22]. We therefore observed the incision healing process in the group that was exposed to the formulation containing the higher ethanol percentage. Our data suggest no effect of this formulation on incision healing and closure.

\section{CONCLUSIONS}

This study suggests that PRF-108 and PRF-110 clearance from the wound is slower than that of the commercial ropivacaine solution. This can explain the high efficacy and prolonged duration of activity of these formulations compared to Naropin. It also suggests that an ethanol concentration of up to $6 \%$ does not affect the efficacy or clearance. Gross observations and detailed histology analysis suggest that the 6\% formulation had no detrimental effects on incision healing. The low concentration of ropivacaine found in the blood following treatment with PRF-108 or PRF-110 suggests that the source of the analgesic activity was due to the high ropivacaine concentration found locally in the wound fluid and was not due to systemic exposure. 
Table 2 Histology observations of the incision 14 days post-incision/dosing

\begin{tabular}{|c|c|c|c|c|c|}
\hline $\begin{array}{l}\text { Group number } \\
\text { and treatment }\end{array}$ & $\begin{array}{l}\text { Animal } \\
\text { number }\end{array}$ & Sample & Epidermis & Dermis + SC & Summary (score) \\
\hline \multirow{12}{*}{$\begin{array}{l}\text { Group } 3 \\
\text { PRF-108/6\% } \\
\text { ethanol }\end{array}$} & \multirow[t]{3}{*}{5} & A & FE with a pustule & Excellent & \multirow[t]{3}{*}{ Excellent healing (4) } \\
\hline & & B & $\mathrm{FE}$ & Excellent & \\
\hline & & $\mathrm{C}$ & FE with a pustule & Excellent & \\
\hline & \multirow[t]{3}{*}{6} & A & FE with a pustule & $\begin{array}{l}\text { A narrow discrete scar; in the deep } \\
\text { dermis and SC wider scarring with } \\
\text { mild mononuclear inflammation } \\
\text { (very good-excellent) }\end{array}$ & \multirow[t]{3}{*}{ Excellent healing (4) } \\
\hline & & B & FE with a pustule & $\begin{array}{l}\text { A narrow discrete scar; a large pustule } \\
\text { nearby probably at suture entry } \\
\text { (excellent) }\end{array}$ & \\
\hline & & $\mathrm{C}$ & FE with a pustule & $\begin{array}{l}\text { A narrow discrete scar; a large pustule } \\
\text { nearby probably at suture entry } \\
\text { (excellent) }\end{array}$ & \\
\hline & \multirow[t]{3}{*}{7} & A & - & $\begin{array}{l}\text { A scar is not identified, complete } \\
\text { healing }\end{array}$ & \multirow[t]{3}{*}{ Very good healing (3) } \\
\hline & & B & FE with pustule & $\begin{array}{l}\text { A narrow discrete scar; near it a } \\
\text { suture tract, below it a small focus } \\
\text { of granulomatous and lesser } \\
\text { neutrophilic inflammation with } \\
\text { some amphophilic material (good) }\end{array}$ & \\
\hline & & $\mathrm{C}$ & HF with pustule & $\begin{array}{l}\text { A narrow scar; no inflammation } \\
\text { (excellent) }\end{array}$ & \\
\hline & \multirow[t]{3}{*}{8} & A & HF with pustule & $\begin{array}{l}\text { A somewhat wide area of fibrosis in } \\
\text { dermis and SC, suture cavity, } \\
\text { minimal inflammation (very good) }\end{array}$ & \multirow[t]{3}{*}{$\begin{array}{l}\text { Good-very good } \\
\text { healing }(2-3)\end{array}$} \\
\hline & & B & HF with pustule & $\begin{array}{l}\text { Scar not clearly identified, an area of } \\
\text { fibrosis in deep dermis with an } \\
\text { epidermal inclusion (from suture) } \\
\text { and mild inflammation (good-very } \\
\text { good) }\end{array}$ & \\
\hline & & $\mathrm{C}$ & HF with pustule & $\begin{array}{l}\text { A somewhat wide area of fibrosis in } \\
\text { dermis and SC, multifocal mild to } \\
\text { moderate mononuclear } \\
\text { inflammation in SC (good) }\end{array}$ & \\
\hline
\end{tabular}


Table 2 continued

\begin{tabular}{|c|c|c|c|c|c|}
\hline $\begin{array}{l}\text { Group number } \\
\text { and treatment }\end{array}$ & $\begin{array}{l}\text { Animal } \\
\text { number }\end{array}$ & Sample & Epidermis & Dermis + SC & Summary (score) \\
\hline \multirow[t]{6}{*}{$\begin{array}{l}\text { Group } 1 \\
\text { sham-operated } \\
\text { animals }\end{array}$} & \multirow[t]{3}{*}{9} & A & HF with pustule & $\begin{array}{l}\text { A narrow scar in deep dermis to HF, } \\
\text { mild fibrosis in SC, a small suture } \\
\text { tract (excellent) }\end{array}$ & \multirow[t]{3}{*}{ Good healing $(2)^{\mathrm{a}}$} \\
\hline & & $\mathrm{B}$ & HF with pustule & $\begin{array}{l}\text { A narrow fibrous scar immediately } \\
\text { next to a suture tract with many } \\
\text { neutrophils, suggestive of bacterial } \\
\text { infection (poor) }\end{array}$ & \\
\hline & & $\mathrm{C}$ & FE, large pustules & $\begin{array}{l}\text { A discrete scar is not identified; } \\
\text { moderate fibrosis without } \\
\text { inflammation (good) }\end{array}$ & \\
\hline & \multirow[t]{3}{*}{10} & A & FE with pustule & $\begin{array}{l}\text { A somewhat wide scar without } \\
\text { inflammation (very good) }\end{array}$ & \multirow[t]{3}{*}{ Very good healing (3) } \\
\hline & & $\mathrm{B}$ & $\mathrm{FE}$, large pustules & $\begin{array}{l}\text { Moderate fibrosis in dermis and SC } \\
\text { with minimal inflammation, suture } \\
\text { tract (good) }\end{array}$ & \\
\hline & & $\mathrm{C}$ & FE with pustule & $\begin{array}{l}\text { A narrow and discrete scar, next to it } \\
\text { a tract (excellent) }\end{array}$ & \\
\hline
\end{tabular}

Each sample was evaluated in three sections: sample A is approximately $1 \mathrm{~cm}$ from the marked (proximal) edge; sample B is from the middle; sample $\mathrm{C}$ is approximately $1 \mathrm{~cm}$ from the contralateral distal edge

$F E$ fully epithelialized, $H F$ hair follicle, $S C$ subcutis/subcutaneous

${ }^{a}$ Neutrophilic infiltration suggestive of the presence of bacterial infection

\section{ACKNOWLEDGMENTS}

Sponsorship for this study and for the article processing charges associated with this publication was provided by PainReform (Herzeliya, Israel). All named authors meet the International Committee of Medical Journal Editors (ICMJE) criteria for authorship for this manuscript, take responsibility for the integrity of the work as a whole, and have given final approval for the version to be published.

Disclosures. Sigal Meilin is an employee of MD Biosciences. Michael Naveh and Arnon Aharon were employees of PainReform at time when this study was executed. David Castel and Ofer Doron have nothing to disclose.
Compliance with ethics guidelines. The study was approved by the Institutional Animal Care and Use Committee (IACUC) and adhered to guidelines of the Committee for Research and Ethical Issues of the International Association for the Study of Pain (IASP).

Open Access. This article is distributed under the terms of the Creative Commons Attribution-NonCommercial 4.0 International License (http://creativecommons.org/licenses/ by-nc/4.0/), which permits any noncommercial use, distribution, and reproduction in any medium, provided you give appropriate credit to the original author(s) and the source, provide a link to the Creative Commons license, and indicate if changes were made. 


\section{REFERENCES}

1. Bajwa SJS, Haldar R. Pain management following spinal surgeries: an appraisal of the available options. J Craniovertebr Junction Spine. 2015;6(3):105-10.

2. Essving P, Axelsson $\mathrm{K}$, Kjellberg J, Wallgren O, Gupta A, Lundin A. Reduced hospital stay, morphine consumption, and pain intensity with local infiltration analgesia after unicompartmental knee arthroplasty. Acta Orthopaedica. 2009;80(2):213-9.

3. Aasbø V, Thuen A, Raeder J. Improved long-lasting postoperative analgesia, recovery function and patient satisfaction after inguinal hernia repair with inguinal field block compared with general anesthesia. Acta Anaesthesiol Scand. 2002;46(6):674-8.

4. Li X, Zhou M, Shi X, Yang H, Li Y, Li J, Yang M, Yuan $\mathrm{H}$. Local anaesthetic wound infiltration used for caesarean section pain relief: a meta-analysis. Int J Clin Exp Med. 2015;8(6):10213-24.

5. Erichsen CJ, Vibits H, Dahl JB, Kehlet H. Wound infiltration with ropivacaine and bupivacaine for pain after inguinal herniotomy. Acta Anaesthesiol Scand. 1995;39(1):67-70.

6. Castel D, Willentz E, Doron O, Brenner O, Meilin S. Characterization of a porcine model of post-operative pain. Eur J Pain. 2014;18:496-505.

7. Zimmermann M. Ethical considerations in relation to pain in animal experimentation. Acta Physiol Scand. 1983;554:221-33.

8. Sullivan TP, Eaglstein WH, Davis SC, Mertz P. The pig as a model for human wound healing. Wound repair regen. 2001;9:66-76.

9. Marquet F, Bonneau M, Pascale F, Urien C, Kang C, Schwartz-Cornil I, Bertho N. Characterization of dendritic cells subpopulations in skin and afferent lymph in the swine model. PLoS One. 2011;6(1):e16320.

10. Obreja O, Schmelz M. Single-fiber recordings of unmyelinated afferents in pig. Neurosci Lett. 2010;470(3):175-9.

11. Di Giminiani P, Petersen LJ, Herskin MS. Nociceptive responses to thermal and mechanical stimulations in awake pigs. Eur J Pain. 2012;7(5):638-48.

12. Di Giminiani P, Petersen LJ, Herskin MS. Characterization of nociceptive behavioural responses in the awake pig following UV-B-induced inflammation. Eur J Pain. 2014;18(1):20-8.
13. Castel D, Sabbag I, Brenner O, Meilin S. Peripheral neuritis trauma in pigs: a neuropathic pain model. J Pain. 2015. doi:10.1016/j.jpain.2015.09.011.

14. Swindle M, Makin A, Herron A, Clubb F Jr, Frazier K. Swine as models in biomedical research and toxicology testing. Vet Pathol. 2011;49(2):344-56.

15. Vigneau A, Salengro A, Berger J, Rouzier R, Barranger E, Marret E, Bonnet F. A double blind randomized trial of wound infiltration with ropivacaine after breast cancer surgery with axillary nodes dissection. BMC Anesthesiol. 2011;11:23.

16. Griffiths JD, Le1 NV, Grant S, Bjorksten A, Hebbard $\mathrm{P}$, Royse C. Symptomatic local anaesthetic toxicity and plasma ropivacaine concentrations. BJA. 2013;110(6):996-1000.

17. Bianconi M, Ferraro L, Traina GC, Zanoli G, Antonelli T, Guberti1 A, Ricci1 R, Massari L Pharmacokinetics and efficacy of ropivacaine continuous wound instillation after joint replacement surgery. BJA. 2003;91(6):830-5.

18. Fang-Fang L, Xiao-Ming L, Xiao-Yu L, Jun T, Li J, Wei-Yan L, Li-Dong Z. Postoperative continuous wound infusion of ropivacaine has comparable analgesic effects and fewer complications as compared to traditional patient-controlled analgesia with sufentanil in patients undergoing non-cardiac thoracotomy. Int J Clin Exp Med. 2015;8(4):5438-45.

19. Nasr DA, Abdelhamid HM, Mohsen M, Aly AH. The analgesic efficacy of continuous presternal bupivacaine infusion through a single catheter after cardiac surgery. Ann Card Anaesth. 2015;18(1):15-20.

20. Kluba T, Hofmann F, Bredanger S, Blumenstock G, Niemeyer T. Efficacy of post-operative analgesia after posterior lumbar instrumented fusion for degenerative disc disease: a prospective randomized comparison of epidural catheter and intravenous administration of analgesics. Orthoped Rev. 2010;2:e9.

21. Gulle E, Skärvinge C, Runberg K, Robinson Y, Olerud C. Pharmacological strategies to reduce pruritus during postoperative epidural analgesia after lumbar fusion surgery-a prospective randomized trial in 150 patients. Patient Saf Surg. 2011;5:10-5.

22. Fitzgerald DJ, Radek KA, Chaar M, Faunce DE, DiPietro LA, Kovacs EJ. Effects of acute ethanol exposure on the early inflammatory response after excisional injury. Alcohol Clin Exp Res. 2007;31(2):317-23. 